\title{
The sociocultural aspects of takeaway food consumption in a low-socio- economic ward in the large metropolitan city of Manchester: A grounded theory study
}

\author{
J. Blow, S. Patel and R. Gregg \\ Department of Health Professions, Manchester Metropolitan University, Manchester, M15 6BG
}

Takeaway and fast foods now make up a considerable proportion of the UK diet ${ }^{(1)}$. Frequent consumption of takeaway and fast foods promotes poor health outcomes ${ }^{(2,3)}$ and is associated with poorer diet quality ${ }^{(4)}$. Food choice is a contextual, dynamic, and temporally situated activity which is also a socially constructed act, and all food we consume is permeated with symbolic meaning ${ }^{(5)}$. The present research aimed to qualitatively explore the sociocultural factors that influence the consumption of takeaway foods.

The study employed constructivist grounded theory methodology to collect and analyse qualitative data. Data were collected using one-to-one semi-structured interviews from an inner-city area of Manchester (Rusholme $+2 \mathrm{~km}$ ) between June and October 2016. All procedures were approved by the research ethics committee at Manchester Metropolitan University. Data collection and analysis were carried out simultaneously. Consequently, data sorting and analysis was implemented by moving between four major processes: coding, memoing, developing themes, and theoretical sorting ${ }^{(6)}$.

Thirteen participants were interviewed (aged 25 to 60 years; female $69 \%$ ). Three superordinate themes were derived from the data. The theme labels represent fundamental influences upon takeaway food consumption (Figure).

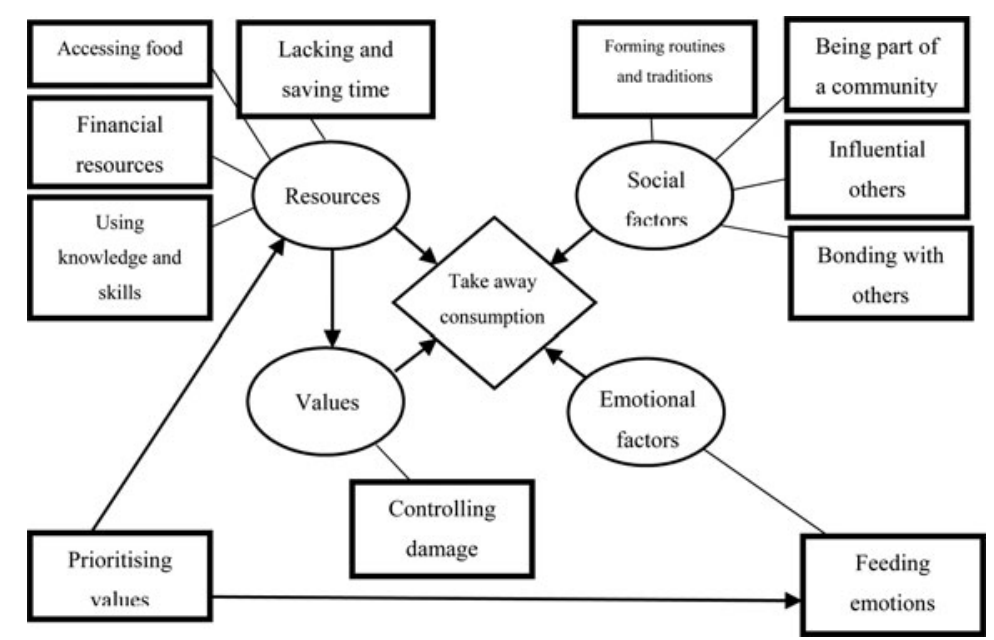

Fig. Thematic map of takeaway meal consumption influences

Interpretation of the results show that pressures on participants time influenced strongly the way that people allocate time for food preparation, and participants expressed an increasing demand for "fast, bulky, hot meals" at all times of the day. Many also expressed a need for healthier options that satisfy these criteria with the same ease as current takeaway food offerings, however, participants enjoy the hedonistic treat that takeaway foods provide. Large portions and low price points are important to this lower-income population, whilst ethnic minority communities require options that are culturally acceptable. Young people were found to be particularly vulnerable to peer influence to consume fast and takeaway foods, especially with takeaway outlets that are targeted towards this demographic.

The evidence that this research has presented can be used by local authorities for the consideration of targeted approaches and interventions that take in to account local sensitivities within the community.

1. Department for Environment Food and Rural Affairs. Family Food 2014. (2015)

2. Duffey KJ, Gordon-Larsen P, Jacobs DR et al. (2007) Am J Clin Nutr 85, $201-208$.

3. Smith K, Blizzard L, McNaughton S et al. (2012) Eur J Clin Nutr 66, 577-84.

4. Smith KJ, McNaughton SA, Gall SL et al. (2009) Int J Behav Nutr Phys Act 629.

5. Berger PL, Luckmann T (1966) The social construction of reality. New York: Anchor Books.

6. Strauss A, Corbin J. (1998) Basics of qualitative research: Techniques and procedures for developing grounded theory. Thousand Oaks: Sage Publications 